\title{
The integrated control strategy for interval Type-2 fuzzy logic power system stabilizer (IT2FLPSS) and compact digital fuzzy automatic voltage regulator (CDF-AVR) in electrical power system
}

\author{
Manoj Kumar Sharma ${ }^{1}$, R.P. Pathak ${ }^{1}$, Manoj Kumar Jha², M.F. Qureshi ${ }^{3 *}$ \\ ${ }^{1}$ NIT Raipur, Chattisgarh, India \\ ${ }^{2}$ Naveen K.T.C. College Salni, Janjgir-Champa, Chattisgarh, India \\ ${ }^{3}$ Department of Electrical Engg., DTE, Raipur, Chattisgarh, India
}

Corresponding Author Email: mfq_pro@rediffmail.com

https://doi.org/10.18280/mmc_a.910404

Received: 20 May 2018

Accepted: 15 September 2018

\section{Keywords:}

interval Type-2 fuzzy logic power system stabilizer (IT2FLPSS), compact digital fuzzy automatic voltage regulator (CDF-AVR), one synchronous machine system, unbalanced loads, conventional AVR(CAVR)

\begin{abstract}
The measure for increasing stability is to improve the main circuits by raising the voltage or employing series capacitors in power transmission lines, but the generator exciter control method, which makes use of a compact digital fuzzy automatic voltage regulator (CDFAVR) and Interval Type-2 Fuzzy Logic Power System Stabilizer (IT2FLPSS), is attracting attention because of its high cost advantage. In this paper the integrated Control strategy for Interval Type-2 Fuzzy Logic Power System Stabilizer (IT2FLPSS) and Compact Digital Fuzzy Automatic Voltage Regulator (CDF-AVR) in Electrical Power System is proposed for Generator Exciter Control. Voltage stability and power quality of the electrical systems depend on proper operation of the Automatic Voltage Regulators (AVR) of generators. Now a days, design technology of the AVRs is being broadly improved. According to wide range operating conditions of the generators and loads, the digital fuzzy AVRs are going to be the modern type of regulators. The previous researches are focused mostly on the balanced loads with minor attention to the unbalanced loads and voltages that are very common for the generating sets embedded in distribution systems.

This work aims to develop a controller based on interval Type-2 fuzzy logic to simulate a compact digital fuzzy automatic voltage regulator (CDF-AVR) in transient stability power system analysis. In this study, performances of a simulated compact digital fuzzy AVR evaluated for a wide range of unbalanced loads operating conditions. It was simulated a one machine control to check if the integrated control operation of interval Type-2 fuzzy logic Power System Stabilizer (IT2FLPSS) and CDF-AVR was possible. After which results were compared to the results obtained with the conventional AVR (CAVR) itself.
\end{abstract}

\section{INTRODUCTION}

AS a result of the increasing capacity and expansion in operating area of power system, together with the increasing constant power load, there is a tendency for both power stability and voltage stability to decline in power system, and this decline has become a pressing issue. Concerning power stability, in particular, the suppression of the 0.3 to $0.5-\mathrm{Hz}$ long period power perturbation that occurs between power systems is being examined closely as a problem that should be solved, in addition to the $1.0 \mathrm{~Hz}$ or so power perturbation that occurs between conventional generators. Here, we describe the latest digital exciter system for generator control that is particularly effective in improving system stability.

According to the standards, the voltage profiles should be kept within the certain limits. Since the voltage profile is consistently varied by load fluctuations so it should be controlled permanently by Automatic Voltage Regulator (AVR). For the generators, an increase in reactive power demand yields some decreases in terminal voltage. This voltage reduction is compensated by some increments in the field current and generating more reactive power through AVR and exciter machine. After that the technologies of the AVRs have been improved greatly. The responding of the old
AVRs to error signals is quiet slow and they are not able to be scheduled using a complicated control strategy.

In 1970 K. j. Runtz applied the digital AVRs to control the field current of a generator. Digital AVRs are flexible and can employ complex methods such as: nonlinear control, neural network, fuzzy logic, genetic algorithm and etc for reliable performance of whole system in various operating conditions of the generating set and loads. Prof. Lotfi Zadeh introduced fuzzy logic theory in 1965. Since then, fuzzy logic theory has been implemented successfully in several applications. Recently, fuzzy logic theory has been used frequently to increase the power capacity, stability and efficiency of the power systems. Nowadays, the fuzzy logic is attended in the structure of automatic voltage regulators and some research has discussed various performance optimization methods engaged for these type regulators. In the present research, a digital fuzzy AVR is simulated in an unbalanced system and its performances are evaluated from different points of view. It is shown that AVR performances are significantly affected by the sampling time, scaling factors and voltage feedbacks. The impacts of these three parameters on the AVR performances are considered here in this study and their optimized values are determined by precise analysis of the simulation results. 


\section{POWER SYSTEM STABILITY AND EXCITER CONTROL}

Power system stability involves voltage stability, in which a constant voltage can be restored and maintained even when changes in load occur, and power stability, in which the power perturbation that arises between generators that are operating in parallel is quickly suppressed and a constant power can be maintained. It is necessary to sufficiently guarantee both types of stability, taking the most severe operating conditions into consideration. The control approach makes it possible to extract the maximum capability of the generator by improving the control algorithm when digital control equipment is used, which has a very large economical effect. From the power system point of view, the excitation system must contribute for the effective voltage control and enhancement of the system stability. It must be able to respond quickly to a disturbance enhancing the transient stability and the small signal stability. The excitation system controls the generated EMF of the generator and therefore controls not only the output voltage but the power factor and current magnitude as well. In many present-day systems the exciter is a dc generator driven by either the steam turbine (on the same shaft as the generator) or an induction motor. An increasing number are solid-state systems consisting of some form of rectifier or thyristor system supplied from the ac bus from an alternator exciter. The voltage regulator is the intelligence of the system and controls the output of the exciter so that the generated voltage and reactive power change in the desired way. In most modern systems the automatic voltage regulator (AVR) is a controller that senses the generator output voltage (and sometimes the current) then initiates corrective action by changing the exciter control in the desired direction. The speed of the AVR is of great interest in studying stability. Because of the high inductance in the generator field winding, it is difficult to make rapid changes in field current. This introduces a considerable lag in the control function and is one of the major obstacles to be overcome in designing a regulating system.

The purpose of this work is the development of an interval Type-2 fuzzy logic Power System Stabilizer (IT2FLPSS) software (IT2FLPSS software) to simulate the compact digital fuzzy automatic voltage regulator (CDF-AVR) behavior. The use of convectional automatic voltage Regulator (CAVR) in synchronous generators to control the terminal voltage and reactive power has been the common phenomena in power systems control. Synchronous generators are nonlinear systems which are continuously subjected to load variations and the AVR design must cope with both normal load and fault condition of operation. Evidently, these conditions of operation result to considerable changes in the system dynamics. When the CDF-AVR with fixed gain is used, the performance worsens and in some cases, introduces negative damping and degraded system stability. So far, a lot of work has been done in synchronous machine excitation stabilization using CDF-AVR and controllers, all geared toward overcoming the problems enumerated above. The short comings here is that the parameters of the controllers are fixed and so if the system dynamics changes as a result of faults, the controller will be tuned manually to adjust. Modern control techniques are used extensively to achieve self-tuning (ST) control in synchronous generators. In this CDF-AVR work, additional signals are used to improve robustness and are generally nonlinear. Of recent, a lot of research is going on in areas of application of soft computing (fuzzy and neural approach) in synchronous generator controls.

This work is based on interval Type-2 fuzzy logic Power System Stabilizer (IT2FLPSS) and CDF-AVR. IT2FLC in synchronous generator terminal voltage and reactive power control is designed so that it has the ability to improve the performance of interval Type-2 fuzzy logic Power System Stabilizer (IT2FLPSS). The interval Type-2 fuzzy logic Power System Stabilizer (IT2FLPSS) is superior to conventional AVR controllers which continue to tune the controller parameters because it will tune and to some extent remember the values that it had tuned in the past.

\section{LOCATION OF CDF-AVR IN POWER PLANT}

Figure 1 below shows a functional block diagram of synchronous generator connected to bus bar through a step-up transformer. It also indicates the terminal voltage/reactive power control loop using automatic voltage regulator (AVR) and the load frequency and real power control (LFC) loop using the governor. During faulted condition, a single machine infinite bus power system shown in Figure 2 is used.

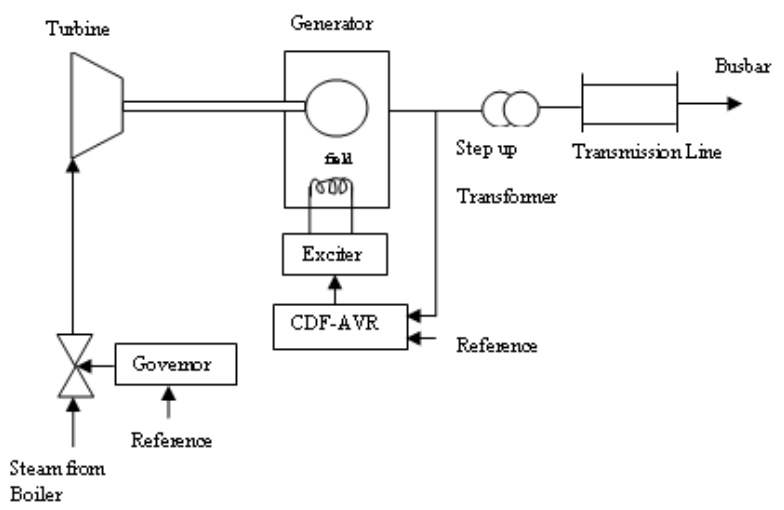

Figure 1. Power system network showing CDF-AVR

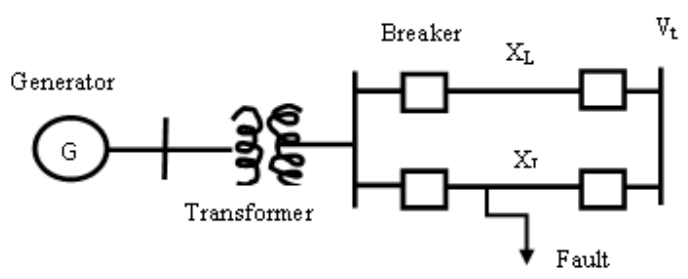

Figure 2. A single machine infinite bus power system

Figure 2 above is used to study the oscillation of the synchronous generator terminal voltage under faulted condition. It has been shown that the dynamic response of synchronous Generator in a practical power system when a fault occurs is very complicated.

\section{COMPACT DIGITAL AUTOMATIC VOLTAGE REGULATOR (CDF-AVR) AND INTERVAL TYPE-2 FUZZY LOGIC POWER SYSTEM STABILIZER (IT2FLPSS)}

In order to accomplish exciter control for power stability, it is necessary to accurately and rapidly measure various types 
of power perturbation data, including the effective power $(P)$, internal frequency $(f q)$, and rotational speed $(\bowtie)$. It is also necessary to implement a control algorithm that can use those input signals to guarantee control for a wide range of power perturbation frequencies $(0.3$ to $1.5 \mathrm{~Hz})$. Figure 3 shows the integrated operation of IT2FLPSS and CDF-AVR for power system stability control, stability includes power stability and voltage stability, improving both of these is important to the operation of a power system.

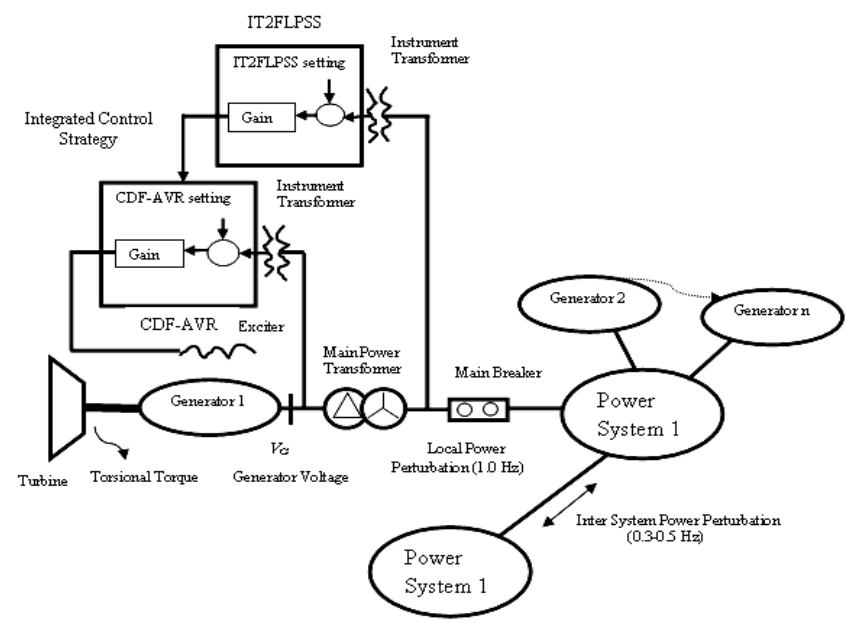

Figure 3. Power systems and stability

Interval Type-2 Fuzzy Logic Power System Stabilizer (IT2FLPSS).

The IT2FLPSS method that is currently widely used is based on the signal $\Delta P$ formula $(\Delta \mathrm{P})$ IT2FLPSS with the effective power as the input. This method is applied to suppress the local power perturbation between generators, which has a power perturbation frequency of about $1.0 \mathrm{~Hz}$. For the low-frequency perturbation that occurs between power systems in wide-area operation, however, there is little system perturbation information included in the active power, so $(\Delta \mathrm{P})$ IT2FLPSS has little effectiveness. As a solution to that problem, $(\Delta \mathrm{P}+\Delta \oplus)$ IT2FLPSS, which uses the internal frequency $\left(f_{q}\right)$ or the rotational speed $(\Phi)$ as well as the active power is effective for low frequencies, was used. However, $₫$ includes turbine and generator system axle torsion fluctuation information as well as system perturbation information, so consideration must be given to the use of a notch filter or other such device when this input is used. The interval type-2 FLC uses interval type-2 fuzzy sets (such as those shown in Figure 4(a) to represent the inputs and/or outputs of the IT2FLPSS. The structure of an IT2FLPSS is depicted in Figure 4(b), it consists of a Fuzzifier, Inference Engine, Rule Base, TypeReducer and a Defuzzifier.

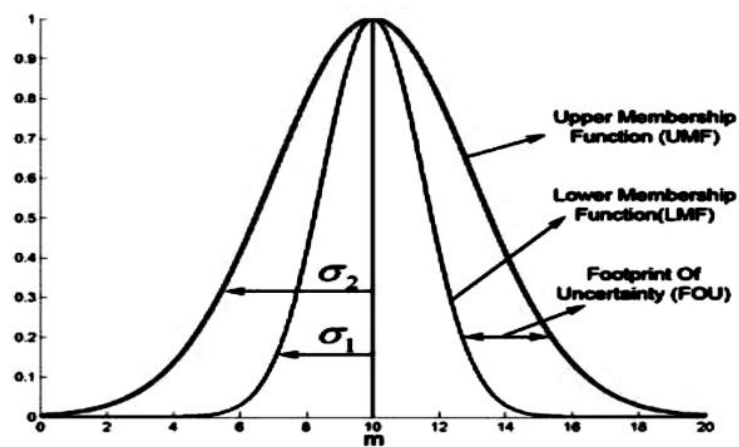

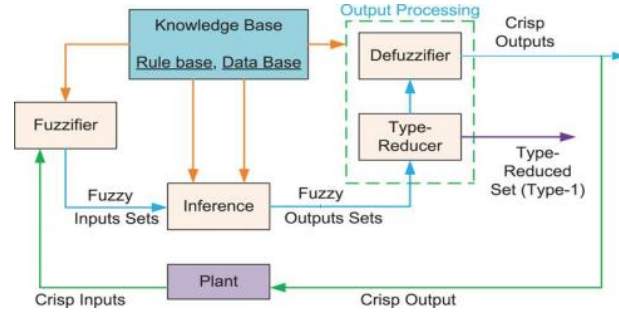

Figure 4. (a) An interval type-2 fuzzy set (b) Structure of the interval type-2 FLPSS

The interval type-2 FLPSS works as follows:

(a) The crisp inputs from the input sensors are first fuzzified into input type-2 fuzzy sets. The input type- 2 fuzzy sets then activate the inference engine and the rule base to produce output type-2 fuzzy sets.

(b)The inference engine combines the fired rules and gives a mapping from input type-2 fuzzy sets to output type-2 fuzzy sets. The type-2 fuzzy outputs of the inference engine are then processed by the type-reducer which combines the output sets and performs a centroid calculation which leads to type-1 fuzzy sets called the type-reduced sets.

(c) After the type-reduction process, the type-reduced sets are defuzzified (by taking the average of the type-reduced set) to obtain crisp outputs that are sent to the actuators.

\section{MODELING AND SIMULATION}

The synchronous generator which represents the plant has an input $\mathrm{u}(\mathrm{kT})$ from the IT2FLPSS and terminal voltage output $\mathrm{y}(\mathrm{kT})$. The input to the IT2FLPSS is the error $e(k T)=r(k T)-$ $y(k T)$ and change in error $\mathrm{c}(k T)=\frac{e(k T)-e(k T-T)}{T}$ where $r(k T)$ is a reference input. Membership functions for Interval Type-2 Fuzzy logic power system stabilizer (IT2FLPSS) inputs $e(k T)$ $\& \mathrm{c}(k T)$ are shown in Figure $6(\mathrm{a}, \mathrm{b}, \mathrm{c} \& \mathrm{~d})$. A fuzzy rules were employed as indicated below in table 1 with triangular membership functions.

Table 1. Decision table interval type 2 fuzzy based PSS

\begin{tabular}{|c|c|c|c|c|c|c|c|}
\hline $\begin{array}{c}\text { Angular } \\
\text { Speed } \\
\text { Dekiation } \\
\text { Angular } \\
\text { Acceleration }\end{array}$ & NHU & NMU & NSU & ZRU & PSU & PMU & PHU \\
\hline NHU & NH & NH & NM & NM & NS & ZR & PS \\
\hline NMU & NH & NM & NM & NS & ZR & PS & PM \\
\hline NSU & NH & NM & NS & NS & ZR & PS & PM \\
\hline ZRU & NH & NM & NS & ZR & PS & PM & PH \\
\hline PSU & NM & NS & NS & PS & PS & PM & PH \\
\hline PMU & NM & NS & ZR & PS & PM & PM & PH \\
\hline PHU & NS & ZR & PS & PM & PM & PH & PH \\
\hline
\end{tabular}

Table 2. Decision table interval type 2 fuzzy based digital AVR

\begin{tabular}{|c|c|c|c|c|c|c|c|}
\hline $\begin{array}{l}\text { Error } \\
\text { Integral } \\
\text { Error }\end{array}$ & NHU & NMU & NSU & ZRU & PSU & PMU & PHU \\
\hline NHU & NH & NH & NH & NH & NM & NS & ZR \\
\hline NMU & NH & NH & NH & NM & NS & ZR & PS \\
\hline NSU & NH & NH & NM & NS & ZR & PS & PM \\
\hline ZRU & NH & NM & NS & ZR & PS & PM & PH \\
\hline PSU & NM & NS & ZR & PS & PM & PH & PH \\
\hline PMU & NS & ZR & PS & PM & PH & PH & PH \\
\hline PHU & ZR & PS & PM & PH & PH & PH & PH \\
\hline
\end{tabular}


In the table above, NH, NM, NS, ZR, PS, PM, PH stands for negative High, negative Medium, negative small, zero, positive small, positive medium, positive High.

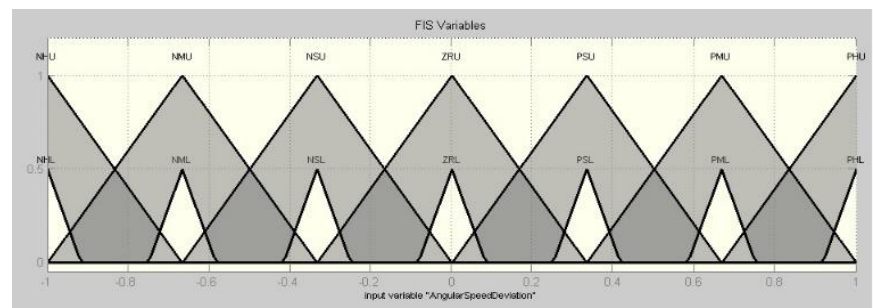

(a) IT2FSPSS Input 1

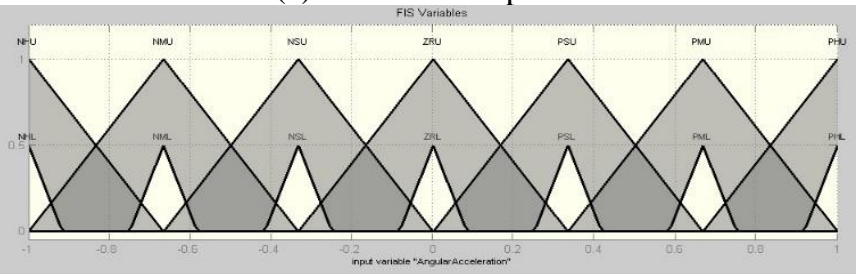

(b) IT2FSPSS Input 2

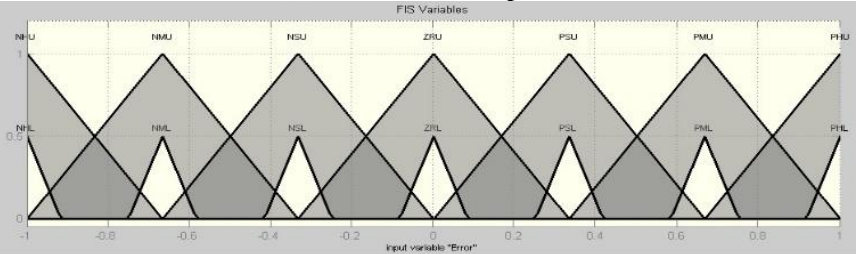

(c) CDFIT2FSAVR Input 1

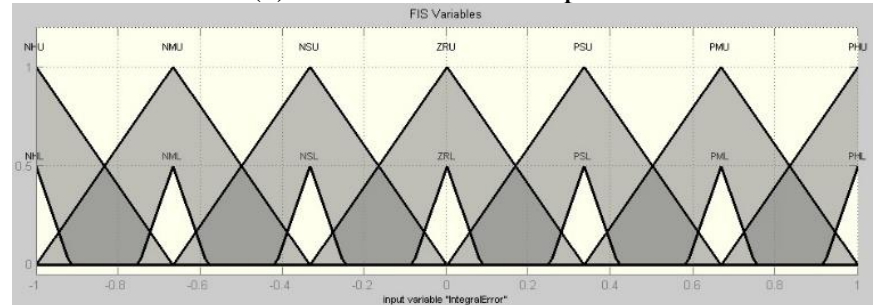

(d) CDFIT2FSAVR Input 2

Figure 6.

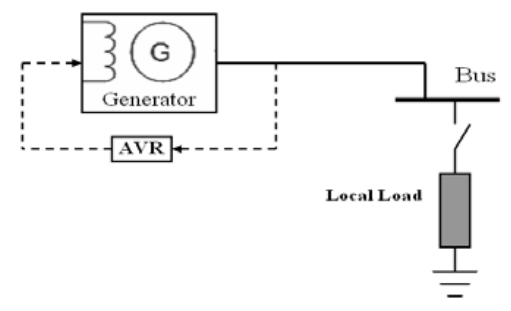

Figure 7. Simulated system

This interval Type-2 Fuzzy logic power system stabilizer (IT2FLPSS) has two input signals, an error signal (e) and its rate of change (de/dt). Error signal is the deviation between the set point (desired value that usually equals to 1PU) and the feedback value. Let us suppose that the error signal and its rate of change vary between -1 to +1 . Rate of change of error signal is applied for quick response of the controller to any rapid and large disturbances. For designing a fuzzy controller, some membership functions are normally specified regarding to the system and experiments.

Since the membership functions of two input signals are 7 and 7, so the rule base of fuzzy controller comprises 49 rules.

Modeling: The system which is developed to study the transient and steady state performance of a fuzzy based compact digital fuzzy AVR consists of a local load supplied by a small synchronous generator (31.5KVA) with an automatic voltage regulator shown in Figure 7. All components of the system are modeled in details.

Dynamic Generator Model: However, the classical third order dynamic generator model has been commonly used for designing the excitation controller. This third order model can be written as follows Mechanical equations

$$
\begin{aligned}
& \dot{\delta}=\emptyset \\
& \dot{\omega}=-\frac{D}{2 H} \oplus+\frac{\infty 0}{2 H}\left(P_{m}-P_{e}\right) \\
& \text { Generator Electrical dynamic } \\
& \dot{E}_{\mathrm{q}}^{\prime}=\frac{1}{T^{\prime} d o}\left(E_{f}-E_{q}\right) \\
& \text { Electrical equations } \\
& E_{q}=\frac{x_{d s}}{x_{d s}} E_{q^{-}} \frac{x_{d}-x^{\prime} d}{x^{\prime} d 0} V_{s} \operatorname{Cos} \delta \\
& P_{e}=\frac{V_{s}}{x_{d s}} E_{q} \operatorname{Sin} \delta, I_{q}=\frac{V_{s}}{x_{d s}} \operatorname{Sin} \delta=\frac{P_{e}}{x_{d s}{ }^{\prime}} \\
& Q_{e}=\frac{V_{s}}{x_{d s}} E_{q} \operatorname{Cos} \delta-\frac{V_{s}{ }^{2}}{x_{d s}} \\
& E_{q}=x_{a d} I_{f} \\
& E_{f}=k_{c} U_{f} \\
& V_{t}=\frac{1}{x_{d s}}\left[x_{s}{ }^{2} E_{q}{ }^{2}+V_{s}{ }^{2} x_{d}{ }^{2}+2 x_{s} x_{d} x_{d s} P_{e} \operatorname{Cos} \delta\right]^{1 / 2} \\
& x_{d s}=x_{d}+x_{T}+x_{L} \quad x^{\prime}{ }_{d s}=x^{\prime}{ }_{d}+x_{T}+x_{L} \\
& x_{s}=x_{T}+x_{L}
\end{aligned}
$$

The definition of the parameters are, $\delta(t)$ power angle of the generator (in radian), $\omega(t)$ relative speed (in $\mathrm{rad} / \mathrm{s}$ ), $P_{m}$ mechanical input power (in p.u), $P_{e}$ active power delivered to bus (in p.u), $E_{q^{\prime}}$ transient EMF in the quadrature axis (in p.u), $V_{t}$ terminal voltage of the generator (in p.u)

A IT2FLPSS for Synchronous Generator Terminal Voltage Control $y=c x$,

Where state variables $\mathrm{x}$ is defined as $x=\left(\Delta \delta, \Delta \omega, \Delta E q^{\prime}\right)$

Governor: Frequency oscillations of the generators have great impact on the stable performance of the machine and system. The frequency oscillation and governor response affect the AVR performance during transient states. The parameters of the governor are:

$\mathrm{a}=0.00016, \mathrm{~b}=0.044, \mathrm{c}=1, \mathrm{R}=0.02, \mathrm{~J}=1, \mathrm{D}=0.01, \mathrm{P}_{\text {base }}$ $=31500, \omega_{\text {base }}=50 \pi$

"Te" the electromagnetic torque is calculated by:

$$
T_{e}=\frac{1}{2}[i]^{T} \frac{d[L(\theta)]}{d \theta}[i]
$$

Digital fuzzy AVR: The block diagram of whole system including a digital fuzzy automatic voltage regulator is shown in Figure 8. The AVR blocks are implemented digitally using a microprocessor. The stabilizer block of the CDF-AVR used here consists of an interval Type-2 fuzzy logic PSS (IT2FLPSS) working in parallel with a digital PI controller as shown in Figure 9. Terminal voltage is mainly settled down by IT2FLPSS and to eliminate the steady state error of the terminal voltage a PI controller is employed. The Mamdani's fuzzy inference method is the one selected for the development of the IT2FLPSS, as it provides more flexibility to implement the control strategy down to finest details.

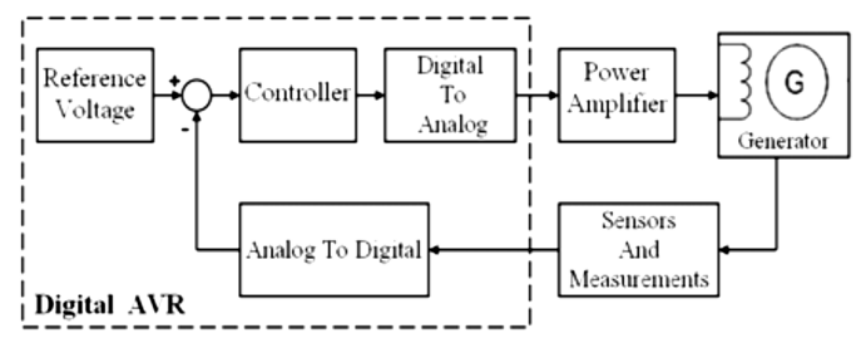

Figure 8. Digital fuzzy AVR of a generator 


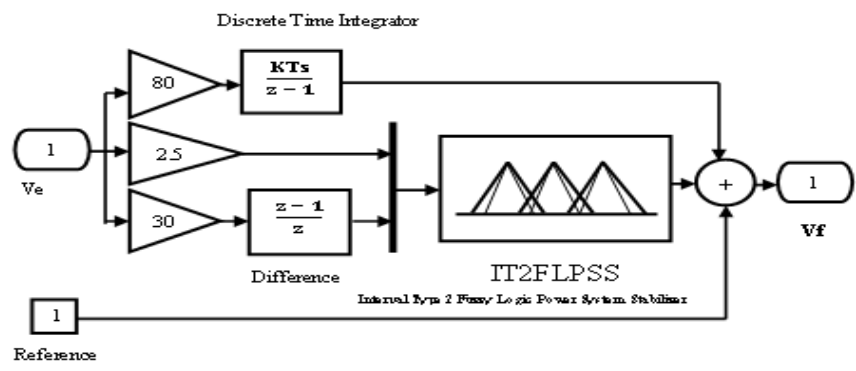

Figure 9. Digital interval Type-2 fuzzy logic power system stabilizer

\section{Simulation:}

Sample time: From three different sampling times of 0.05 , 0.001 and $0.0001 \mathrm{Sec}$, the AVR output signals are shown in Figure 10 for $0.001 \mathrm{Sec}$ when the generator is subjected to a step load.

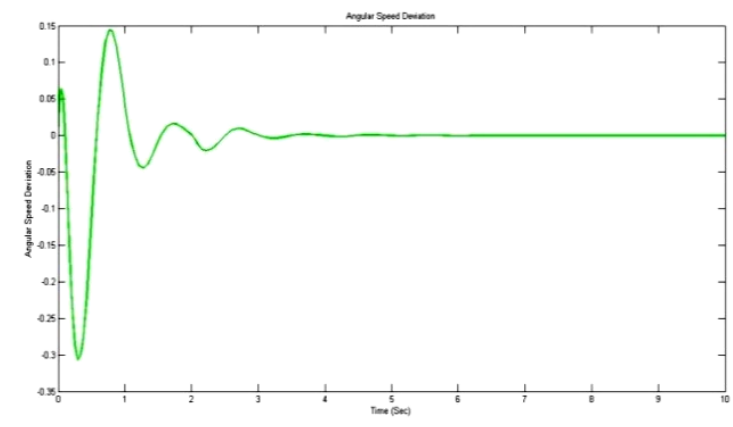

Figure 10. Output signal of the AVR for sample time $\mathrm{T}=0.001 \mathrm{Sec}$

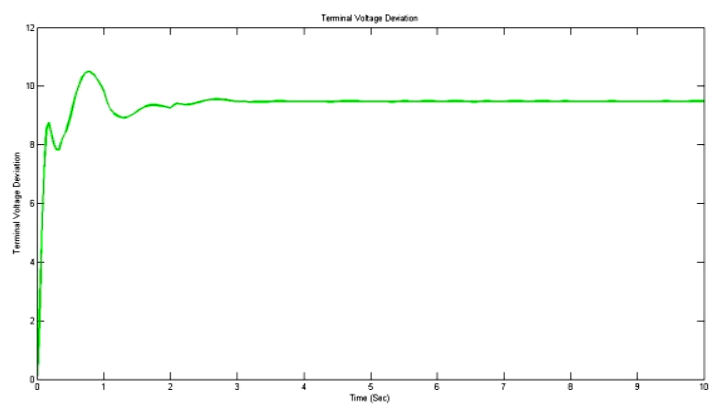

Figure 11. Terminal voltage variations of the generator with different sample times during step load application change

The corresponding terminal voltages for three sampling times are shown in Figure 11 for comparison. The step load used here is a full load with 0.8 lag power factor that applied to a no load generator. Therefore, applying any sampling frequencies higher than $1000 \mathrm{~Hz}$ for a $50 \mathrm{~Hz}$ terminal voltage would be costly and leads to a time consuming product. Briefly for a $50 \mathrm{~Hz}$ systems it can be claimed that $\mathrm{T}=0.001 \mathrm{Sec}$ is the best value for the sample time of the feedback signal.

Scaling factors: . Assignment the proper values for scaling factors is significant due to their great impact on the AVR performances. For this purpose various simulations are carried out and based on a quality evaluation index, approximate optimum values for them are deduced. The index comprises some important factors of the whole system performance surmised in a linear normalized combination such as:
$\mathrm{QF}=\mathrm{PO}+\mathrm{T}_{\mathrm{s}}+\mathrm{AO}_{\max }$

Where QF is quality valuation index, PO is the percentage overshoot of the terminal voltage, Ts is the settling time and $\mathrm{AO}_{\text {max }}$ is the maximum value of the AVR output signal. The optimum values of the scaling factors are 2.5 and 30 for the error signal $\left(\mathrm{E}_{\mathrm{sf}}\right)$ and its rate of change $\left(\mathrm{dE}_{\mathrm{sf}}\right)$.

\section{Multi-Input IT2FLPSS}

As a generator exciter control method for increasing power stability, $(\triangle \mathrm{P})$ IT2FLPSS is widely used, but recently, the $\Delta P+\Delta \omega($ or $\Delta f$ ) method of IT2FLPSS has been made practical for the purpose of wide-area stabilization. However, to guarantee stability in long-distance power transmission systems and to achieve control performance that is not easily affected by changes in system status (robustness), the multiinput IT2FLPSS method, in which the VAR, $\Delta Q$, is added to the $\Delta P+\Delta \omega$ method, was developed by the Central Research Institute of Electric Power Japan. Because, $\Delta Q$ is quite unaffected by system operating conditions compared to $\Delta P$ and contains the angle of the internal phase difference $(\Delta \delta)$ between the system and the generator in nearly constant proportion, it is effective for suppressing the $0.3-$ to $0.5-\mathrm{Hz}$ low-frequency power perturbation that occurs between power systems. In multi-input IT2FLPSS, a circuit for improving transitional stability ( $v$ circuit) is added to achieve an excellent effect for both transitional stability and operating stability. In addition, we were able to confirm that almost the same effect can be obtained if the frequency signal, $f$, of the internal induced voltage of the generator is used in place of the $a$ signal The frequency signal can be detected directly by calculation from the voltage and current. Thus there is no need for equipment that has an electromagnetic sensor, and so multiinput IT2FLPSS can be implemented even in hydroelectric generators, where the installation of an exciter pick-up is difficult.

A conceptual diagram of the wide-area power system model for evaluating stability is shown Figure 12.

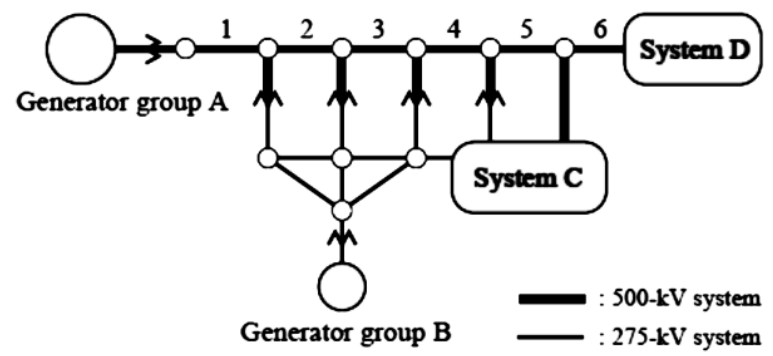

Figure 12. Generator Model System
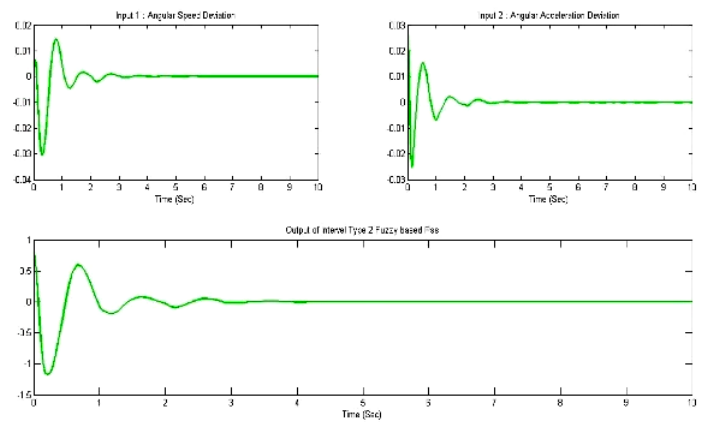

IT2FPss

Figure 13. Experimental Results on Power Stability Improvement (Change in Phase Difference Angle after Excluding System Short-circuit Accidents) 
With multi-input IT2FLPSS, there is little change in the phase difference angle after exclusion of system short-circuit accidents, and there is an excellent increase in both transition stability and operation stability. Concerning the improvement in power stability by application of multi-input PSS compared to the conventional methods, the results of verification experiments performed using the 12-generator model system that is illustrated in Figure 12 are presented in Figure 13.

\section{SIMULATION RESULTS}

The graphs shown in the subsection below will provide the comparative performance results between the conventional AVR control and the Integrated IT2FLPSS+ CDF-AVR one. The analysis is performed on one synchronous machine excitation control done with the MATLAB Software. The output voltage of a synchronous machine is controlled by a conventional AVR (CAVR) applied to its excitation system, in the MATLAB simulation. All data were taken from reference. Next step is to replace the CAVR device by an integrated IT2FLPSS+ CDF-AVR in order to check its efficiency in the synchronous machine excitation voltage control.

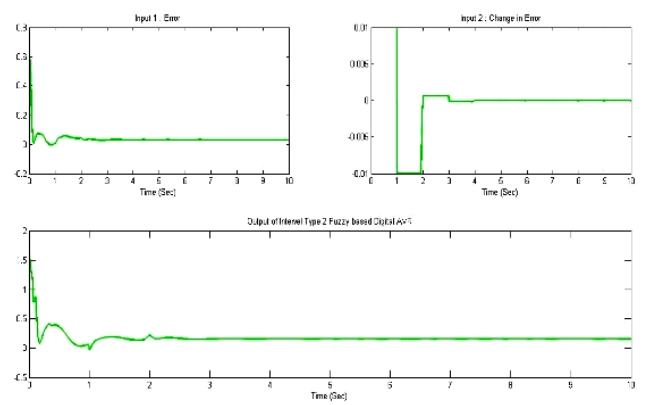

IT2FDigitalAVR

Figure 14. (a) One machine analysis (terminal voltage Vt.) using Integrated IT2FLPSS+ CDF-AVR (b) One machine analysis (load angle) using Integrated IT2FLPSS+ CDF-AVR (c) One machine analysis (electrical torque) using Integrated IT2FLPSS+ CDF-AVR

The rule-base used by IT2FLPSS to simulate a CDF-AVR in the MATLAB program is shown in Table 1. The eleven linguistic variables used were generator voltage error $e(k T)$ and generator voltage error variation $c(k T)$. Figure 14 (a),(b),(c) show the terminal voltage, load angle and electrical torque of a synchronous machine connected to an infinite bus bar by a transmission line.

A step input is applied to a normal CAVR with amplifier transfer function given by

$$
\begin{aligned}
& \frac{K A}{1+\tau A S} \\
& K A=10, \tau \mathrm{G}=0.1, K \mathrm{E}=1, \tau E=0.4 \\
& K G=1, \tau \mathrm{G}=1, K \mathrm{R}=1, \tau R=0.05
\end{aligned}
$$

A stabilizer is connected between the exciter output and the input summer with a step input signal. The parameters above remained the same but the stabilizer has transfer function given by $\frac{s}{0.04 s+1}$

Integrated IT2FLPSS and CDF-AVR is used and the response for a step input is shown in Figure 13 (a) and (b). A three phase fault is applied to the line and cleared after two seconds. Figure 14 (a) and (b) shows the Response of Integrated IT2FLPSS and CDF-AVR to a three phase fault.

\begin{tabular}{|c|c|c|}
\hline Model & $\begin{array}{c}\text { Stability Time for } \\
\text { Terminal Voltage } \\
\text { Deviation (In sec) }\end{array}$ & $\begin{array}{c}\text { Stability Time for } \\
\text { Angular Speed } \\
\text { Deviation (In Sec) }\end{array}$ \\
\hline Pss \& AVR & 5.268 & 5.731 \\
\hline Interval Type 2 & 4.456 & 5.251 \\
Fuzzy based Pss \& \\
AVR
\end{tabular}

\section{CONCLUSION}

In this research, the simulation results of a CDF-AVR of a synchronous generator in balanced and unbalanced load operating conditions are presented. Simulation results for a 50 $\mathrm{Hz}$ network approve that the optimum sampling time for a CDF-AVR is about $\mathrm{T}=0.001 \mathrm{Sec}$. The ripples of CDF-AVR output signal and performance of overall system are improved by this cost effective sampling rate. Moreover, by a variety of simulations, the optimum values of scaling factors for the input signals of the fuzzy controller are determined. The associated gains for voltage error and its rate of change are 2.5 and 30 respectively. Performance evaluations of the characterized Integrated IT2FLPSS and CDF-AVR in unbalanced load operation demonstrate that the voltage feedback has a major contribution in voltage variance.

We have described the Integrated IT2FLPSS and CDFAVR method as specific proposals for improving power system stability by means of generator exciter control. Concerning power system stability, there is a need for development of new automatic parameter setting technology that would make it possible to cope with the advances in system operation from future globalization and the increased diversity and complexity in the load on the generator that comes with it, as well as to cope with changes in system conditions due to temporal considerations, such as daytime, nighttime and the seasons. We intend to continue to accumulate knowledge from experiments with actual machines and operating data and to apply that knowledge in the future.

\section{REFERENCES}

[1] Kitauchi Y, Taniguchi H, Shirasaki T, Ichikawa Y, Amano M, Banjo M. (1999). Experimental verification of multi-input PSS with reactive power input for damping low frequency power swing. IEEE Transactions on Energy Conversion 14(4): 1124-1130. https://doi.org/10.1109/60.815037

[2] Kitauchi Y. (1999). Simulation experiments on a multiinput PSS prototype for suppression of long-period perturbation. Proceedings of the National Convention of the Institute of Electrical Engineers of Japan, 6-276.

[3] Mendoza JE, Morales DA, López RA, López EA, Vannier JC, Coello Coello CA. (2007). Multiobjective location of automatic voltage regulators in a radial distribution network using a micro genetic algorithm. 
IEEE Trans. Power Syst 22(1): 404-412. https://doi.org/10.1109/TPWRS.2006.887963.

[4] Runtz KJ, Farag ASA, Huber DW, Hope GS, Malik OP. (1973). Digital control scheme for a generating unit. IEEE Trans. PAS 92(2): 478-483. https://doi.org/10.1109/TPAS.1973.293747.

[5] Darabi A. (2005). Auxiliary windings, supplying the AVR of a brushless synchronous generator. Proceedings of the Eighth International Conference on Electrical Machines and Systems (ICEMS) 1: 81-85. https://doi.org/10.1109/ICEMS.2005.202489

[6] Wang L. (1996). A course in fuzzy systems and control. Prentice Hall, Paperback.

[7] Mamdani E, Assilian S. (1975). An experiment in linguistic synthesis with a fuzzy logic controller. Int. J. $\begin{array}{lll}\text { Man-Mach. } & \text { Stud. } & \text { 51(1): }\end{array}$ https://doi.org/10.1016/S0020-7373(75)80002-2

[8] Sugeno M. (1985). Industrial applications of fuzzy control. Elsevier Science Inc, New York, NY.

[9] Mamdani EH, Assilian S. (1975). An experiment in linguistic synthesis with a fuzzy logic controller. Int. J. Man Mach. Studies 7(1): 1-13. https://doi.org/10.1016/S0020-7373(75)80002-2

[10] Figueroa J, Posada J, Soriano J, Melgarejo M, Roj S. (2005). A Type-2 fuzzy logic controller for tracking mobile objects in the context of robotic soccer games. Proceeding of the 2005 IEEE International Conference on Fuzzy 359-364. https://doi.org/10.1109/FUZZY.2005.1452420

[11] Hagras H. (2004). A hierarchical Type-2 fuzzy logic control architecture for autonomous mobile robots. IEEE Transactions On Fuzzy Systems 12(4): 524-539. https://doi.org/10.1109/TFUZZ.2004.832538

[12] Liang Q, Mendel J. (2000). Interval Type-2 fuzzy logic systems. Theory and Design; IEEE Transactions on Fuzzy Systems
https://doi.org/10.1109/FUZZY.2000.838681

[13] Lynch C, Hagras H, Callaghan V. (2006). Using uncertainty bounds in the design of an embedded realtime Type-2 neuro-fuzzy speed controller for marine diesel engines. Proceedings of the 2006 IEEE International Conference of Fuzzy Systems, Vancouver, Canada.

[14] Lynch C, Hagras H, Callaghan V. (2006). Embedded interval Type-2 neuro-fuzzy speed controller for marine diesel engines. Proceedings of the 2006 Information Processing and Management of Uncertainty in Knowledge-based Systems conference: 1340-1347.

[15] Mendel J. (2001). Uncertain rule-based fuzzy logic systems. Prentice Hall.

[16] Mendel J, John R. (2002). Type-2 fuzzy sets made simple. IEEE Transactions on Fuzzy Systems 10: 117-127. https://doi.org/10.1109/91.995115

[17] Wan TW, Kamal DH. (2006). On-line learning rules for type-2 fuzzy controller. Proceedings of the 2006 IEEE International Conference of Fuzzy Systems, Vancouver, Canada.

[18] Wu D, Tan WW. (2005). Type-2 FLS modeling capability analysis. Proceedings of the 2005 IEEE International Conference on Fuzzy Systems: 242-247. https://doi.org/10.1109/FUZZY.2005.1452400

[19] Wen JY, Cheng SJ, Malik OP. (1998). A synchronous generator fuzzy excitation controller optimally designed with a genetic algorithm. IEEE Transactions on Power $\begin{array}{lll}\text { Systems } & 13(3) \text { : 884-889. }\end{array}$ https://doi.org/10.1109/59.708763

[20] Ruhua Y, Hassan J, Eghbali M, Hashem N. (2003). An online adaptive neuro-fuzzy power system stabilizer for multi-machine systems. IEEE Transactions on Power System 18(1): $128-135$ 